\title{
Erratum to: Bayesian Networks-based Shield TBM Risk Management System: Methodology Development and Application
}

\author{
Heeyoung Chung*, In-Mo Lee**, Jee-Hee Jung ${ }^{* * *}$, and Jeongjun Park**** \\ Received May 8, 2018/Revised July 6, 2018/Accepted July 14, 2018/Published Online November 30, 2018
}

Erratum to: KSCE Journal of Civil Engineering (2019) 23(1): $452-465$

DOI 10.1007/s12205-018-0912-y

This erratum is published to notify an error of a reference which was cited in-text, but not mentioned in the references section. See revised reference below:

\section{Errata:}

Jung, J. H., Chung, H., Kwon, Y. S., and Lee, I. M. (2019). “An ANN to predict ground condition ahead of tunnel face using TBM operational data." KSCE Journal of Civil Engineering, Vol. 23, No. 7, pp. 3200-3206, DOI: 10.1007/s12205-019-1460-9.

The original article has been corrected.

*Ph.D. Student, School of Civil, Environmental and Architectural Engineering, Korea University, Seoul 02841, Korea (E-mail: hy317@korea.ac.kr)

**Member, Professor, School of Civil, Environmental and Architectural Engineering, Korea University, Seoul 02841, Korea (E-mail: inmolee@korea.ac.kr)

***Member, Ph.D. Student, School of Civil, Environmental and Architectural Engineering, Korea University, Seoul 02841, Korea (E-mail: jeehee83@korea.ac.kr)

****Senior Researcher, Advanced Infrastructure Research Team, Korea Railroad Research Institute, Uiwang 16105, Korea (Corresponding Author, E-mail: jjpark@krri.re.kr) 